\title{
A PROBLEMÁTICA DOS AMERICANISMOS: TEORIAS DE DIVISÃO DIALETAL, ANÁLISE DE DADOS E UMA PROPOSTA PARA A MARCAÇÃO DIATÓPICA DO DICIONÁRIO DE FALSOS AMIGOS ESPANHOL - PORTUGUÊS The issue on Americanisms: dialect division theories, data analysis and a proposal for diatopic marking in Spanish-Portuguese dictionaries of false cognates
}

\author{
Michelle Kuhn Fornari*
}

Este trabalho está inserido em um projeto de pesquisa que almeja a elaboração de um dicionário de falsos amigos Espanhol - Português. ${ }^{1}$ A questão abordada diz respeito à marcação diatópica proposta no nosso dicionário e será tratada a partir do estudo da fragmentação do Espanhol da América e das imputações diatópicas oferecidas pelos dicionários de americanismos.

Na primeira parte deste trabalho, será traçado um panorama dos métodos de divisão dialetal do Espanhol Americano, buscando uma melhor compreensão em relação à problemática da variação existente na língua. Em seguida, analisaremos o tratamento dessas teorias na marcação diató-

Aluna do curso de Licenciatura em Letras - Hab. professor - Português e Espanhol e bolsista do programa Pibic/CNPq - UFRGS no projeto de pesquisa "Dicionário de falsos amigos Espanhol-Português" sob a orientação do Prof. Dr. Félix Valentín Bugueño Miranda.

Para uma definição macroestrutural (critérios de seleção) do dicionário de falsos amigos tanto no que diz respeito ao Espanhol como no que se refere ao Português, ver Bugueño (2001) e Bugueño (2003). 
pica de três dicionários de americanismos. Na segunda parte, apresentaremos uma proposta de marcação diatópica baseada no resultado obtido com essa pesquisa teórica que se refere às divisões dialetais e a análise de dados supracitados.

A dialetologia hispano-americana proporciona um vasto campo de pesquisa no que diz respeito à formação do Espanhol da América. O problema dos americanismos pode ser analisado com base nos métodos de divisão dialetal disponíveis, a partir do ponto de vista de cada um deles.

Ureña (1921) (apud MORENO, 1988, p. 118) apresenta uma classificação baseada na distribuição geográfica das principais famílias de línguas indígenas presentes durante a colonização espanhola. Segundo essa teoria, o fator mais relevante para o desenvolvimento dos dialetos americanos são os substratos indígenas que hipoteticamente influenciaram a formação do Espanhol Americano. Os critérios utilizados por Ureña (1921) para estabelecer suas cinco zonas dialetais são: substrato lingüístico (contato com uma língua indígena), proximidade entre as regiões (critério geográfico) e laços que uniram as regiões durante a dominação espanhola (critério político-cultural). o principal elemento distintivo é o vocabulário. A divisão dialetal de Ureña (1921) se caracteriza por cinco zonas dialetais: ${ }^{2}$

1. México, incluindo Novo México e a maioria da América Central (Nahua);

2. Caribe - Antilhas e regiões costeiras da Colômbia e Venezuela (Arahuaco);

3. Terras altas da América do Sul, desde Colômbia até Bolívia e o Norte do Chile (quéchua);

4. Centro e Sul do Chile (mapuche/ araucano);

5. Países do Rio da Prata: Argentina, Uruguai e Paraguai (guarani).

Lipski (1994, p. 19) chama a atenção para o fato de que as zonas de Ureña (1921) apresentam tanto unidade quanto diversidade, mas a principal crítica à teoria do substrato lingüístico parte de Rona (1964) (apud MORENO, 1988, p. 121), que considera os critérios seguidos por Ureña (1921) subjetivos e extralingüísticos, isto é, por causa do caráter lingüístico dos dialetos, Rona (1964) defende a idéia de que estes devem ser teorizados a partir de fatos objetivos e a base para essa teoria deve ser igualmente de caráter predominantemente lingüístico. ${ }^{3}$

Cf Lipski (1994, p. 18).

Uma visão baseada em dados extralingüísticos é a de Malmberg (1974, p. 145), que aponta fatores políticos, sociais e culturais dentre as características que determinaram as diferentes formações do Espanhol da América. 
A influência do substrato indígena na estruturação do Espanhol americano é relativa, pois uma língua se estrutura em diferentes níveis: fonético-fonológico, morfossintático e lexical. Para que se possa falar em influência do substrato indígena, é necessário avaliar essa influência em relação a todos esses níveis. É fato que houve mescla de população e de línguas em algumas zonas, mas não é possível afirmar o quanto essas línguas tiveram contato. Sabe-se que lexicalmente a influência é considerável, mas em outros níveis, provavelmente, não se tem influência considerável do substrato. ${ }^{4}$ Além disso, Rona (1964) alerta para o fato de que não se pode restringir a cinco as famílias de línguas na América que exercem influência no espanhol americano, pois podem-se considerar mais de cem que exerceram e ainda exercem influência no espanhol.

Outra divisão fundamentada na geografia, porém de caráter puramente exógeno, ${ }^{5}$ é a teoria das "terras altas por terras baixas ou costa" e influência climática, disputa entre Wagner (1920) e Ureña (1921). Wagner (1920) (apud MORENO, 1988, p. 28) acreditava no predomínio andaluz na conquista e na colonização da América, e, no que diz respeito à pronúncia, acreditava em uma enorme influência da região de Andaluzia. Seu argumento é que os colonos teriam buscado um clima parecido ao que estavam acostumados na Metrópole, ou seja, espanhóis de terras altas e frias estabeleceram-se nas cidades montanhosas interioranas e espanhóis de terras baixas e quentes (andaluzes) fixaram-se nas costas. Esse método de divisão dialetal liga as diferenças entre as terras altas e baixas americanas com a região de origem dos colonos espanhóis.

Essa teoria enfraquece por dois motivos principais. O primeiro é que as zonas climáticas da Espanha não se relacionam tanto com a pronúncia como se constata na América. Por exemplo, Extremadura, região da Espanha fria, montanhosa e afastada do mar que se caracteriza pela redução das consoantes, característica muito presente no espanhol americano falado na costa. Também é considerável o fato de que algumas regiões andaluzas se parecem no que diz respeito ao clima com as zonas altas da América Hispânica. O segundo motivo que colabora para o enfraquecimento da teoria é o fato de que não é alta a probabilidade de que os colonos tenham procurado no novo mundo um clima parecido ao que eram submetidos na península.

Por outro lado, a teoria se sustenta graças à vontade dos colonos de manter o mesmo tipo de trabalho que tinham na Espanha. Se isso de fato

\footnotetext{
4 Segundo Lapesa (1988, p. 556), "la contribución más importante y segura de las lenguas indígenas está en el léxico."

Consideramos teorias exógenas aquelas baseadas em critérios extralingüísticos, tais como o clima, a geografia e laços políticos ou culturais. Teorias endógenas são aquelas baseadas em critérios puramente lingüísticos, tais como o substrato indígena ou traços fonéticos.
} 
ocorreu, pode ter contribuído para uma distribuição territorial que mantém semelhanças climáticas com a Metrópole, pois do clima dependiam muitas das atividades profissionais.

Outro ponto importante que sustentaria a teoria é o fato de que chegavam elementos lingüísticos à costa da América com as pessoas envolvidas com atividades marítimas na Espanha, ou seja, chegavam de pessoas que viviam em Andaluzia, enquanto pessoas ligadas ao clero, militares e estudantes provenientes do Norte da Espanha chegavam às regiões interioranas, onde estavam os centros administrativos da América. Isso também pode ter contribuído para a semelhança fonológica entre as regiões costeiras da América.

Acreditamos ser inegável a influência do espanhol de Andaluzia na estruturação do espanhol americano, mas é preciso salientar que a única evidência que se pode perceber de maneira precisa é o seseo, ${ }^{6}$ pois outros traços fonéticos, morfossintáticos e lexicais não permitem chegar com absoluta segurança a uma conclusão andaluza. ${ }^{7}$ Preferimos apoiar a idéia de que o espanhol andaluz é apenas um dentre muitos elementos que contribuíram para a formação do espanhol da América, adotando, assim, uma explicação poligenética ${ }^{8}$ para tal fenômeno. A partir dessa explicação, podemos considerar o Espanhol Americano como o resultado de uma constante evolução.

Considerando o fato de que o sotaque ${ }^{9}$ é o traço que mais facilita a distinção em relação aos dialetos americanos, novamente Ureña (1921) (apud LIPSKI, 1994, p. 23) e Honsa (1975) (apud LIPSKI, 1994, p. 23) propõem teorias baseadas em traços fonéticos. Ureña (1921) relacionou a perda ou manutenção do /s/ de final de sílaba e a distribuição geográfica desse traço para delimitar a fragmentação lingüística do Espanhol Americano. Honsa (1975) baseou-se na presença ou ausência do fonema / $\lambda$ / e na realização do /s/ de final de sílaba para a sua classificação.

Rona (1964) (apud MORENO, 1988, p. 121) foi o primeiro a formular uma teoria combinando traços fonéticos com o voseo ${ }^{10}$ e suas variáveis

\footnotetext{
6 Seseo é um fenômeno que consiste em não diferenciar / / / e /c/ ou / z/, pronunciando sempre o som referente ao fonema fricativo interdental surdo. (1988, p. 563-570).

Uma boa síntese a respeito do andalucismo hispano-americano está em Lapesa

8 Acreditamos na influência de diversos fatores na fragmentação do Espanhol Americano, mas não podemos afirmar com exatidão quais ou quantos contribuíram. o termo poligenético diz respeito a uma divisão dialetal gerada por diversos aspectos lingüísticos (por exemplo, as línguas indígenas) e extralingüísticos (tais como proximidade entre regiões).

9 Conforme Trask (2004), sotaque é um modo particular de pronunciar uma língua. Cada tipo distinto de pronúncia é chamado de sotaque. da América.

${ }_{10}$ Voseo é um fenômeno consistente na troca de tú por vos e se dá em grande parte
} 
morfológicas. Sua classificação é baseada na distribuição de traços individuais. Rona (1964) nega a existência de zonas dialetais nítidas na América, defendendo a idéia de que, de fato, o que há são superposições, apresentando, dessa maneira, uma modificação no método de investigação, em que a determinação das zonas é feita a partir de isoglosas.

Com tais procedimentos, Rona (1964) (apud MORENO, 1988, p. 121) estabelece dezesseis zonas e considera áreas de convivência com o inglês ou de dialetalismos crioulos e áreas de dialetos mesclados com o português, formando mais sete zonas, resultando um total de vinte e três zonas. As críticas à classificação de Rona (1964) dizem respeito principalmente à falta de contigüidade - segundo Zamora e Guitart (1982) (apud MORENO, 1988, p. 123), "la contigüidad se considera un requisito para incluir diferentes regiones dentro de la misma zona, salvo que lo único que las separe sea el mar." - e à desproporção na dimensão geográfica entre algumas zonas, a exemplo uma comparação entre a zona 1 (México, Antilhas, costas caribenhas da Colômbia e da Venezuela e metade oriental do Panamá) e a zona que só abrange a parte ultra-serrana do Uruguai.

Zamora e Guitart (1982) (apud MORENO, 1988, p. 123), influenciados pelos métodos de divisão utilizados por Rona (1964), apresentam também uma teoria baseada em variáveis morfofonológicas. O critério é absolutamente lingüístico, ou seja, trata-se de uma teoria de caráter endógeno. Os elementos distintivos são três traços: dois fonéticos, aspiração ou conservação do /s/ de final de sílaba e a realização velar ou glotal do /x/, e um morfossintático, presença ou ausência do voseo ou convivência com o tuteo. Assim como no trabalho de Rona (1964), nesse estudo não é utilizado nenhum aspecto do léxico, pois "as isoglosas se tornam menos sistemáticas dentro do conjunto da linguagem". ${ }^{11}$

O resultado se reparte em 9 zonas: ${ }^{12}$

1. Zona do Caribe, incluindo costa do México, Colômbia, leste do Panamá;

2. Terras altas do México;

3. América Central, oeste do Panamá;

4. Interior da Colômbia, Venezuela andina;

5. Costa do Pacífico da Colômbia, Equador;

6. Costa do Peru;

11 Cf Rona (1964) (apud MORENO, 1988, p. 122).

12 Cf Lipski (1994, p. 31). 
7. Altiplano do Peru, Equador, Bolívia, noroeste da Argentina;

8. Chile;

9. Paraguai, leste da Bolívia, Uruguai, maioria da Argentina.

Por fim, Cahuzac (1980) (apud LIPISKI, 1994, p. 33) apresenta uma divisão do espanhol da América baseada em dados lexicais. Partindo de uma lista de 184 termos utilizados para designar os homens do campo, retirada de dicionários de americanismos, procede-se à definição apontando-se o âmbito geográfico da palavra, ou seja, definindo o termo como usado em toda a América, somente em um país, vários países, etc. Para Cahuzac, (1980), a linguagem dos homens do campo se origina das regiões espanholas, tendo uma distribuição geográfica na América que não apresenta uniformidade.

Essa teoria também apresenta um caráter exógeno e se aproxima da teoria de "terras altas por terras baixas ou costa", pois se baseia nas regiões espanholas e na sua influência na formação do Espanhol Americano. As críticas dirigidas à teoria semântico-léxica de Cahuzac (1980) se referem à confiabilidade duvidosa dos dicionários de americanismos, de onde foram retiradas as palavras, definições e marcação diatópica. Também é importante salientar que somente o ambiente camponês e o que lhe diz respeito não é suficiente para fundamentar uma divisão dialetal.

Todas a teorias esboçadas acima partem do princípio de que existe uma variação no Espanhol da América, mas nenhuma delas consegue dar conta da explicação para este fato. ${ }^{13}$ Segundo Mounton (2001), "las propuestas difieren mucho una de las otras em función de los critérios de partida. Todas son enriquecedoras, pero ninguna de ellas es concluyente y otras nuevas podrían siempre matizar o mejorar las anteriores." A primeira pergunta que podemos nos fazer é se essa variação é fruto do substrato indígena ou da influência peninsular.

Considerando a enorme extensão territorial da América Latina e a grande variação detectada na pronúncia e no léxico, consideramos necessário que se proponham esquemas de classificação, mas, em vista da quantidade de falhas que apresentam as teorias dialetais disponíveis, sugerimos como solução provisória para o estudo da fragmentação lingüística do Espanhol da América a classificação por países, embora, obviamente, saibamos que a variação dialetal não pára nos limites entre uma nação e outra. Esse tipo de divisão é meramente descritivo e tem o objetivo de percorrer os traços de cada país americano de língua espanhola. Esse esforço por parte 
dos pesquisadores e dialetólogos de teorizar a variação lingüística na América ainda não encontra um reflexo na maioria dos dicionários. ${ }^{14}$

Passamos a analisar três dicionários de americanismos: ${ }^{15}$ Mo (1983), EvAm (1987) e SoAm (1983), buscando um reflexo que as teorias de divisão dialetal possam ter provocado em suas marcações diatópicas. É possível observar que Mo (1983) baseia-se muito na questão do substrato lingüístico, apontando quase sempre empréstimos das línguas indígenas, o que não é tão freqüente em EvAm (1987) e SoAm (1983), como se pode perceber no tratamento da palavra acabiray em Mo (1983):

acabiray (Del guarani acá, “cabeza”, y birá, “rojiza”). m. Arg (NE), Par. Buitre de cabeza pelada, Cathartes aura. $\square$ La voz es nombre guaraní que se usa esporádicamente en la zona de influencia del guaraní.

Mo (1983)

Mo (1983) aponta em sua marcação diatópica o Paraguai e apenas o Nordeste da Argentina. SoAm (1983) considera a palavra recorrente em toda a América e EvAm (1987), diferentemente de ambos, aponta toda a Argentina e o Uruguai, sem menção ao Paraguai, apontado por Mo (1983). A marcação diatópica de EvAm (1987), nesse caso, é extremamente questionável:

acabiray n. m. Zool. Ornitol. (Argent., Urug., Río de La Plata). Especie de buitre, de color pardo oscuro.

EvAm (1987)

Aqui se pode salientar a desorganização da marcação diatópica, que traz além de "Argentina" e "Uruguai”, a marca "Río de La Plata". Há, no mínimo, uma redundância, afinal, os países formadores da região do Rio da Prata são Uruguai, Argentina e Paraguai. Dessa forma, fica evidenciada uma falha relacionada à ausência do Paraguai na marca, uma vez que tal país faz parte da região do Rio da Prata. Acreditamos que a melhor opção seria escolher entre a marca "Argent., Urug." e a marca "Río de La Plata".

14 Werner (2001) desenvolve um estudo crítico a respeito da produção lexicográfica do Espanhol Americano, trazendo questões de fundo social e apontando tarefas a serem executadas e espaços a serem preenchidos, em busca daquilo que denomina "una producción diccionarística profesional en todos los aspectos".

15 Os dicionários de americanismos utilizados serão referidos pelas siglas Mo (Morínigo), EvAm (Everest) e SoAm (Sopena). Também serão referidos os dicionários-padrão da Língua Espanhola Diccionário de la Real Academia Española (DRAEe) e Diccionario de usos del Español (DUE). Com isso, seguimos a tendência geral da metalexicografia (cf. HARTMANN, 2001, p. 11). 
Também se pode chamar a atenção para a discordância entre os três dicionários. Em princípio, a única unanimidade é a Argentina, mas ainda assim não em sua totalidade, afinal, Mo (1983) só considera a região nordestina do país. Enquanto EvAm (1987) aponta o Uruguai, Mo (1983) aponta o Paraguai em sua marcação diatópica, evidenciando assim a falta de confiabilidade proveniente dessa modalidade de dicionário.

No caso da palavra farra, outra selecionada para a análise, chamamos a atenção para uma discrepância muito grande nas marcações diatópicas de cada dicionário, como se pode observar:

farra. n.f. (Argent., Colomb., Chile, Ecuad., Perú). Jarana, juerga, parranda. n.f. (Argentina, Uruguay). Burla.

EvAm (1987)

farra (Voz del portugués brasileño, "orgía ruidosa".)f. Arg., Bol., Col., Chi.,Ecu., Par., Per., Uru. vulg. Juerga. Jarana. /2/ Arg., Uru. Burla. Titeo. /3/ Tomarlo para la FARRA. Tomarle el pelo.

Mo (1983)

farra. f. $\square$ 1. Holgorio, diversión. Bulliciosa. $\square 2$. Titeo, burla.

SoAm (1983)

Mo (1983) aponta a etimologia da palavra, considerando-a como originária do português brasileiro, e aponta ainda sua primeira acepção como recorrente em Argentina, Bolívia, Colômbia, Chile, Equador, Paraguai, Peru, Uruguai. EvAm (1987) considera apenas Argentina, Colômbia, Chile, Equador e Peru, sem menção à Bolívia e ao Paraguai. SoAm (1983), como é característico, considera a acepção como recorrente em toda a América.

Outro problema é a marca de uso presente em Mo (1983), que aponta a acepção como vulgar. Em EvAm (1987) não consta nenhuma marca de uso, assim como em SoAm (1983), o que também é uma incoerência, considerando que o conteúdo semântico é o mesmo nos três dicionários. A discrepância se realiza entre os três dicionários, tanto no âmbito da marcação diatópica quanto no âmbito da marcação diastrática.

Em seguida, analisamos a palavra farrear e verificamos uma incompatibilidade em suas marcações diatópicas:

farrear $v$. intr. (Amér., Argent., Chile). Andar de farra o de parranda.

EvAm (1987) 
farrear. intr. Arg., Chi., Ecu., Par., Uru. Andar de farra o juerga. /2/ Arg., Uru. Burlarse de una persona. /3/ $r$. Malbaratar los bienes en parrandas. < Fulano SE FARREó el dinero de la cosecha.>

Mo (1983)

farrear. (de farra, holgorio). $\square$ 1.v. intr. Jaranear. $\square 2$. v. tr. Malbaratar, malvender la hacienda. $\square 3$. v. $r$. Burlarse, mofarse de alguno.

SoAm (1983)

No que se refere a Mo (1983), é questionável que a marcação diatópica de farrear ( $1^{\mathrm{a}}$ acepção) não seja a mesma da palavra farra (1 ${ }^{\mathrm{a}}$ acepção). Mo (1983 s.v.) não considera Colômbia e Peru, países apontados em farra (Mo 1983 s.v.). Isso poderia significar que a palavra farra foi produtiva (em termos de derivação) em todos os países marcados, enquanto na Colômbia e no Peru não houve derivação (considerando que o verbo derivou-se do substantivo). Tal fenômeno é possível, mas essa afirmação não passa de uma inferência que se dá a partir de dados que não apresentam muita confiabilidade. Tal confusão não acontece na segunda acepção para farra de Mo (1983), "burla, titeo", em que a marcação diatópica diz respeito a Argentina e Uruguai, como em farrear, segunda acepção. Temos, nesse caso, coerência:

farra /2/ Arg., Uru. Burla. Titeo.

farrear /2/ Arg., Uru. Burlarse de una persona.

Mo (1983)

A discrepância aparece, porém, em EvAm (1987), que em farrear não aponta uma segunda acepção. Tanto Mo (1983) quanto SoAm (1983) apresentam três acepções para a palavra, SoAm (1983) considerando todas como de uso recorrente em toda a América e Mo (1983) apontando as marcações diatópicas.

Outro problema detectado na única acepção de EvAm (1987) para farrear é sua marcação diatópica (Amér., Argent., Chile). Há uma incoerência semelhante à observada na palavra acabiray. EvAm (1987) alude primeiro à América, depois especifica Argentina e Chile, como se ambos não fizessem parte do continente americano. Ou a palavra é recorrente em toda a América, o que inclui Argentina e Chile, ou apenas nos dois países.

No tratamento da palavra cahuín acontece um problema, mas relacionado à sua etimologia: 
cahuín. *n. m. (Chile, voz araucana). Concurrencia de gente en la que se da el bullicio y la borrachera.

EvAm (1987)

cahuín. (Del guaraní ca'ú, "borrachera”, e in, “agua”.) m. Chi. Borrachera. /2/ Reunión de gente alegre. $\triangle$ En todos los pueblos guaraníes cauí era el nombre de la chicha de maíz.

Mo (1983)

cahuín. (Del araucano cahuiñ, comida o bebida con que se celebra una obra nueva.). m. 1. Borrachera, o comilona compañada de borrachera. 20. adj. Fig. Chismoso. Ú.t. c. s. [3. Andar en cahuines. frs. fig. y fam. Andar metido en enredos.

SoAm (1983)

EvAm (1987) e SoAm (1983) apontam cahuín como uma palavra de origem araucana. Na classificação de Ureña (1921), a zona de influência araucana (zona 4) inclui o centro e o sul do Chile, logo, a marcação diatópica de EvAm (1987) parece ser coerente. Mo (1983) remete cahuín à influência guarani, inclusive chamando a atenção para a significação da palavra nos povos guaranis, "nombre de la chicha de maíz", o que parece relacionar-se com o significado da palavra em espanhol, "borrachera". Uma explicação também lógica e coerente traz SoAm (1983), ao esclarecer a etimologia de cahuín ("del araucano cahuiñ , comida o bebida con que se celebra una obra nueva”), que certamente tem algo em comum com a definição "borrachera, o comilona compañada de borrachera." o problema etimológico parece insolucionável, pois é possível que a palavra seja de origem guarani e tenha sido abarcada pelo léxico araucano, ou vice-versa.

Há, ainda, um desencontro de acepções no que diz respeito a esses três dicionários. Mo (1983) parece dividir em duas a acepção de EvAm (1987) "concurrencia de gente en la que se da el bullicio y la borrachera." Contudo, SoAm (1983) exclui a segunda acepção de Mo (1983) e acrescenta uma ("2. adj. Fig. Chismoso. Ú.t. c. s."), além da expressão idiomática ("3. Andar en cahuines. frs. fig. y fam. Andar metido en enredos").

Não pretendemos, neste trabalho, analisar a qualidade das definições, ${ }^{16}$ mas sim apontar as falhas que contêm esses dicionários no que diz respeito às suas marcações diatópicas, mas também, é claro, analisar as definições e verificar sua coerência quanto à significação apresentada em 
cada um dos dicionários selecionados. O tratamento da palavra cajeta, por exemplo, é um caso muito complexo tanto no que se refere à marcação diatópica quanto no que se relaciona à coerência de suas definições:

cajeta. * $n . f$. (Amér.) Caja en la que se venden postres.

EvAm (1987)

cajeta. f. Ant., Cent., Méx. Dulce, jalea o turrón que tiene la forma del molde en que se cuajó. /2/ Caja en que se venden estos dulces. 13/ Cub. Caja para tabacos. /4/ Arg., Par. La vulva de la mujer. /5/ adj. Cos., Ecu. Que tiene la quijada o el labio inferior muy saliente. /6/Méx. Pusilánime. Cobarde.

Mo (1983)

cajeta. (dim. de caja). F. 1. Caja de tabaco, tabaquera. 2. Persona que tiene el labio o la quijada muy saliente; befo. $\mathbf{0}$. Caja redonda con tapa que se usa para echar dulces y jaleas, y tambien el dulce o jalea que contiene. 4 . De cajeta. m. adv. De modo excelente, muy bien. Salió de cajeta el negocio.

SoAm (1983)

A primeira acepção de SoAm (1983), sem marcação diatópica, característica deste dicionário, encontra par na terceira de Mo (1983), relacionada a Cuba, mas em EvAm (1987) tal acepção não existe. A segunda acepção de SoAm (1983) se encontra em Mo (1983), relacionada à Costa Rica e ao Equador, mas igualmente não consta em EvAm (1987). A terceira acepção de SoAm (1983) ("Caja redonda con tapa que se usa para echar dulces y jaleas, y tambien el dulce o jalea que contiene”) parece ser igual à primeira de Mo (1983), ("Dulce, jalea o turrón que tiene la forma del molde en que se cuajó”) e à única de EvAm (1987) (“Caja en la que se venden postres”). Contudo, EvAm (1987) e Mo (1983) (que parece separar um significado em duas definições, primeira e segunda) fazem alusão ao ato da venda da sobremesa ou doce. SoAm (1983) não se refere a isso em sua definição, trazendo a dúvida quanto à veracidade dessas informações.

O problema diatópico aparece também de forma bastante notável. Em SoAm (1983), temos três acepções e uma expressão idiomática consideradas como de uso recorrente em toda a América, o que se repete em EvAm (1987). Mo (1983), ao contrário, marca suas acepções diatopicamente, trazendo, inclusive, duas acepções a mais, uma para o México ("Pusilánime. Cobarde".) e uma para Argentina e Paraguai ("La vulva de la mujer".), ambas não registradas por EvAm (1987) e SoAm (1983). 
Um problema similar acontece ao analisar a palavra calcha dentro desses três dicionários. Todos trazem a definição "conjunto de prendas de vestir y cama de los trabajadores". Mo (1983) acrescenta à definição "y aun piezas del apero de montar", enquanto SoAm (1983) a divide em duas definições (acepções 3. "pl. Conjunto de las prendas de vestir y cama de los trabajadores." e 4. "Piezas del apero de montar.”). O problema se dá na marcação diatópica, pois EvAm (1987) marca Argentina e Chile, Mo (1983) marca apenas o NO da Argentina e SoAm (1983) considera, como já sabemos, uso recorrente em toda a América. SoAm (1983) aponta, ainda, a marca de uso no plural, enquanto EvAm (1987) e Mo (1983) não fazem a isso nenhuma referência.

Outra acepção encontrada nos três dicionários para calcha é "plumas em patas y dedos de las aves”, cuja marcação diatópica coincide em EvAm (1987) e Mo (1983) e se refere ao Chile. Para SoAm (1983), uso recorrente em toda a América.

A segunda acepção de Mo (1983) (“/2/ Chi. Cerneja. Pelo largo en los caballos por encima del vaso".) só é encontrada em SoAm (1983) ("1 Cerneja, mechón de cerdas cortas y espesas, que tienen las caballerías sobre las cuartillas de los pies y las manos. Ú. m. en pl.”). Mo (1983) marca como uma palavra de uso recorrente no Chile, e há ainda outra discrepância em relação a SoAm (1983), pois este faz referência a um uso mais freqüente no plural. Mo (1983) acrescenta mais duas definições ("/4/ Pelo que cubre la frente". e "/5/ Harapos, jirones que cuelgan de la ropa".), sem referência em EvAm (1987) e SoAm (1983).

O problema da marcação diatópica está presente em grande parte dos "americanismos", ainda que os três dicionários concordem quanto à etimologia da palavra, como no caso de callampa:

callampa. *n. f. (Chile, voz quechua). Seta, hongo. *n. f. (Chile). Barraca. *n. f. (Chile). Sombrero de fieltro.

EvAm (1987)

callampa. (Voz quichua, "hongo"). f. Col., Chi., Per. Hongo comestible. /2/ Chi. Sombrero de fieltro.

Mo (1983)

callampa. (del quichua ccallampa). f. 1 1. Hongo, seta. 2. fig. y fam. Sombrero de fieltro. 3 . Oreja grande. 4 . Punta de la regadera.

SoAm (1983) 
Na primeira acepção, EvAm (1987) considera apenas o Chile, Mo (1983) acrescenta Colômbia e Peru. Na acepção "sombrero de fieltro", EvAm (1987) e Mo (1983) concordam quanto à marcação diatópica, referindo o Chile. Contudo, o problema se dá na marca de uso apontada por SoAm (1983), "figurado e familiar", a que Mo (1983) e EvAm (1987) não fazem alusão. EvAm (1987) acrescenta ainda a definição "barraca”, marcada diatopicamente para o Chile. SoAm (1983) também apresenta acepções não encontradas em EvAm (1987) e Mo (1983), "oreja grande" e "punta de la regadera".

Callana, uma palavra que, segundo os três dicionários, tem origem quéchua, apresenta grave problema de marcação diatópica, como se pode observar na primeira acepção de cada um:

callana. *n. f. (Amér., voz quechua). Vasija rudimentaria que emplean los indios para tostar el maíz y trigo. *n. f. (Chile). Reloj de bolsillo grande. *n. f. (Perú). Maceta, tiesto.

EvAm (1987)

callana. (Voz quichua, "olla chata") f. Arg (NO), Col., Chi., Ecu., Per. Cazuela muy chata que se usa para hacer el casabe, tostar el maíz, cocer el pan de maíz y otros usos similares. Vr. Cayana. /2/ Chi. fest. Reloj grande de bolsillo. /3/ Per. Resíduo del mineral que se beneficia. /4/Vasija rota usada como tiesto.

Mo (1983)

callana. (voz quichua). f. 1 . Vasija tosca en que los indios americanos tuestan maíz o trigo. 2. Manchas callosas que se dice tienen los descendientes de negros o zambos en las nalgas. 13. Escoria metalífera que se beneficia. 4 . Crisol para ensayar metales. $\mathbf{\square}$. Tiesto. 6. Calentador, reloj de bolsillo demasiado grande.

SoAm (1983)

EvAm (1987) e SoAm (1983) consideram callana como de uso recorrente em toda a América, enquanto Mo (1983) restringe seu uso a Argentina, Colômbia, Chile, Equador e Peru. O que temos, de fato, é uma enorme discrepância quanto à marcação diatópica entre EvAm (1987) e SoAm (1983) e Mo (1983).

A conclusão a que chegamos com base nessa breve análise é que não se tem a aplicação de qualquer teoria de divisão dialetal para a elaboração dos atuais dicionários de americanismos, o que torna as marcações diatópicas extremamente questionáveis e pouco confiáveis. Assim como 
nenhuma teoria de divisão dialetal dá conta de explicar a formação do espanhol da América, os dicionários de americanismos não têm um guia confiável que conduza suas imputações diatópicas.

Trazendo a problemática para a construção de um dicionário de falsos-amigos, ${ }^{17}$ foi necessário desenvolver uma proposta para a marcação diatópica a ser aplicada. Conforme Isaza Calderón (1976) (apud MORENO, 1988, p. 198), "os Americanismos são palavras e locuções de significado único usadas em determinadas áreas da América e que não pertencem ao espanhol geral, ou palavras que na América tenham um conteúdo semântico peculiar".

A partir do estudo realizado com as marcações diatópicas em três dicionários de americanismos, verificamos muitas discrepâncias, o que diminui o grau de confiabilidade das informações. O objetivo da segunda parte deste trabalho é apresentar uma forma de proporcionar mais segurança na marcação diatópica do nosso dicionário e, para tanto, os dicionários de americanismos disponíveis no mercado não serão utilizados como única fonte de consulta.

Foi já explicado que não existe uma teoria abrangente e coerente para o estabelecimento de zonas dialetais, assim como já expusemos que as marcas diatópicas resultam pouco confiáveis em grande parte dos dicionários disponíveis. Em busca de uma solução para as imputações diatópicas do nosso dicionário, optamos pela marcação por países, embora tenhamos consciência de que a variedade lingüística do Espanhol Americano ultrapassa fronteiras geográficas. Canfield (1988) utiliza esse método para formar uma compilação de traços fonéticos do Espanhol da América, organizando-a por países e inclusive trazendo mapas de variações fonéticas de cada país.

Em relação aos dicionários impressos, é pertinente salientar que recolhemos a bibliografia standard sobre o tema. Ficaram de fora duas obras: a) O dicionário de Francisco de Santa Maria (Diccionario de americanismos, México, DF, 1942), que julgamos muito antigo, apesar do prestígio

17 Falsos amigos são palavras escritas e/ou pronunciadas de forma muito parecida e muitas vezes até igual - nas duas línguas, porém divergentes no que diz respeito à semântica. Um exemplo clássico de tal fenômeno é embarazada/ embaraçada. Pronunciadas igualmente em espanhol e em português, diferenciam-se na ortografia por apenas uma letra. No entanto, seus significados são totalmente distintos, podendo causar dificuldade ao estudante da língua estrangeira. Nosso dicionário pretende amenizar o grau dessa dificuldade. Para tanto, divide-se em três partes: no primeiro segmento são geradas equivalências para as significações em comum nas duas línguas, ou seja, os verdadeiros amigos. No segmento dois, são geradas definições redatadas em espanhol para as acepções do português. No terceiro segmento são elaboradas definições redatadas em português para as acepções do Espanhol. Os falsos amigos, portanto, constituem os segmentos dois e três do dicionário. Para mais informações acerca do conceito de "falsos amigos" e da estrutura do dicionário, ver Bugueño (1999; 2000; 2002; 2003). 
que já teve nos estudos sobre o Espanhol da América, e b) os dicionários que se derivam do projeto de Augsburgo (Günther HAENSCH et al., 1983, passim) aos quais, por razões orçamentárias, não temos acesso. Além do mais, dado o fato de que não há volumes prontos para todos os países da América e de que cada volume se esgota nas fronteiras nacionais, precisaríamos da coleção completa para fazer as imputações diatópicas necessárias.

Quanto aos dicionários disponíveis na internet, consideramos que não são completamente rigorosos e não apresentam resultados homogêneos, mas são uma ferramenta de contraste da qual dispomos no momento. Tratase, portanto, de procurar uma complementaridade entre as obras de referência de cunho acadêmico com esses repertórios léxicos que às vezes são mais curiosidades léxicas que repertórios filologicamente fundados.

Gostaríamos de lembrar que foi justamente a impossibilidade de junção entre um panorama dialetológico complexo (o objeto de estudo propriamente dito) e os próprios instrumentos metodológicos (os dicionários de americanismos) que fizeram Günther Haensch desistir de um dicionário "panamericanístico". ${ }^{18}$ Por isso, a única coisa a fazer até o presente momento é comprovar os resultados oferecidos até agora pelos dicionários de americanismos. O que possibilita essa comprovação, ainda que saibamos que não é completamente confiável, é a pesquisa na internet, que, por outro lado, não se pode negar, reflete de alguma forma a língua em uso.

Nossa proposta para proceder à marcação diatópica do dicionário de falsos amigos Espanhol-Português consiste na pesquisa de usos em sites na internet. ${ }^{19} \mathrm{~A}$ partir das informações contidas nos dicionários de americanismos, buscamos a confirmação desses dados na internet. No caso da palavra argolla, encontramos diferentes marcações diatópicas para a mesma acepção:

argolla f. C.Rica, Ecuad., Hond., Perú. Camarilla (Conjunto de personas que influyen subrepticiamente en los asuntos de Estado o en las decisiones de alguna autoridad superior.)

DRAEe (2001)

18 Tanto Mouton (2001) como Werner (2001) salientam justamente o fato de não contarmos ainda com subsídios teórico-metodológicos para uma tarefa assim.

19 É importante salientar que a pesquisa no Google é feita país por país, ou seja, se desejamos procurar a significação de argolla em sites do Equador, selecionamos em ferramentas do idioma a opção de buscar em sites apenas do Equador. No caso de o país não constar na lista, acrescentamos na busca a extensão site:ec, que gera o mesmo efeito: apenas páginas do Equador serão buscadas. Também é importante ressaltar que temos o cuidado de verificar se os textos nos quais fazemos a confirmação das marcações são, de fato, textos relacionados ao país em questão ou se são textos estrangeiros. Por exemplo, na busca em sites do Equador, verificamos se não há nada relacionado à Espanha ou a qualquer outro país da América no contexto em que se encontra a palavra que desejamos confirmar. 
argolla f. C. Rica, Perú. Camarilla (Grupo de personas influyentes.)

DUE (1996)

argolla f. fig. Agrupación política o comercial que pretende obtener honores, lucros etc.

SoAm (1983)

A partir desses dados, buscamos a confirmação dessas marcações diatópicas. DRAEe (2001) e DUE (1996) concordam quanto à marcação de argolla - nesta acepção - para Costa Rica e Peru, e DRAE (2001) ainda aponta Equador e Honduras. SoAm (1983) tem a peculiaridade de considerar todas os americanismos como recorrentes em toda a América, sem apontar países ou regiões específicas. No site de pesquisa Google, buscamos a palavra argolla apenas em páginas em espanhol e do países em questão, um de cada vez.

Na pesquisa realizada para a confirmação de uso dessa acepção de argolla na Costa Rica, obtivemos a confirmação da marcação diatópica apontada por DRAEe (2001) e DUE (1996). ${ }^{20}$

O Equador não faz parte da lista de países presentes na marcação diatópica de DUE (1996), constando apenas em DRAEe (2001). Buscando a confirmação da indicação do dicionário da Real Academia Espanhola, chegamos à conclusão de que a informação procede. ${ }^{21} \mathrm{O}$ Peru é indicado tanto por DRAEe (2001) quanto por DUE (1996) nas suas marcações diatópicas. Nesse caso, também conseguimos chegar à confirmação. ${ }^{22}$

O último país indicado pela marcação diatópica de DRAEe (2001) é Honduras, onde constatamos que não há uso de tal acepção entre os falantes. Os dados recolhidos indicam um uso metafórico da primeira acepção da palavra segundo o DRAEe (2001): "Aro grueso, generalmente de hierro, que, afirmado debidamente, sirve para amarre o de asidero". Essa acepção não é exclusivamente do Espanhol Americano, mas pertence ao Espanhol geral, formando, inclusive, o "verdadeiro amigo" com o português. ${ }^{23}$

A partir do resultado da pesquisa, geramos nossa marcação diatópica considerando apenas os países onde foi possível confirmar as informações. No caso da acepção analisada acima para a palavra argolla, optamos por marcar diatopicamente a palavra para Costa Rica, Equador e Peru,

\footnotetext{
Para verificação de exemplos, ver anexo 1. Para verificação de exemplos, ver anexo 2. Para verificação de exemplos, ver anexo 3. Para verificação de exemplos, ver anexo 4.
} 
desconsiderando a marcação de DRAEe (2001) para Honduras. Outro caso estudado foi o da palavra acabado.

DRAEe (2001) traz duas acepções com a marcação diastrática de coloquialidade, marcada diatopicamente para o Uruguai:

acabado m coloq. Ur. Semen (conjunto de espermatozóides).

acabado m coloq. Ur. Orgasmo (culminación del placer sexual)

DRAEe (2001).

Essas duas acepções não constam em nenhum outro dicionário, apenas em DRAEe (2001). Pela pesquisa de uso, constatamos que a palavra não parece ser utilizada com essas significações no Uruguai. Outro fator que torna a marcação diatópica ainda menos confiável é o fato de que no próprio banco de dados da Real Academia Espanhola (CREA) não consta esse uso de acabado. A partir dessas pesquisas, a solução pela qual optamos foi retirar essas duas acepções do nosso dicionário de falsos amigos.

No caso da palavra capear, ocorre uma situação análoga à anterior. DUE (1996), DRAEe (2001), e SoAm (1983) apontam uma significação pertencente ao espanhol da Guatemala, mas com a pesquisa no Google foi possível verificar que a acepção marcada diatopicamente não se confirma, uma vez que nenhum único registro é encontrado. Curiosamente, no banco de dados da Real Academia Espanhola, ao pesquisar o uso da palavra especificamente na Guatemala, o resultado que se obtém é "no existen casos para esta consulta", ou seja, o banco de dados não registra nenhuma ocorrência de tal acepção. Com base nessas pesquisas, também optamos por retirar a acepção do nosso dicionário.

É importante salientar que os dicionários de americanismos funcionam como ponto de partida para a elaboração da nossa marcação diatópica, assim, a pesquisa nos sites da internet se restringe à confirmação dos dados que retiramos desses dicionários, como se fossem uma espécie de corpus e guia para a resposta que procuramos.

A pesquisa de uso se dá de forma a garantir que a nossa marcação diatópica esteja de acordo com a língua atual, evitando significações em desuso e chegando o mais próximo possível da confiabilidade que pretendemos passar ao nosso leitor-consulente. A pesquisa por países que realizamos no Google é fundamental porque ainda não existe um corpus no que se refere aos americanismos.

É preferível ser prudente na marcação diatópica, apoiando-se em dados empíricos, a trazer imputações que não têm nenhum exemplo, que não se sustentam em nenhum dado prático, como o que acontece com as 
palavras há pouco referidas, acabado e capear, que, embora estejam marcadas diatopicamente em DRAEe (2001), nada consta no CREA para garantir tais imputações.

\title{
RESUMO
}

Neste trabalho propomos uma metodologia para proceder à marcação diatópica do dicionário de falsos amigos Espanhol Português da forma mais confiável possível. Como ponto de partida, apresentamos uma visão panorâmica a respeito das propostas de divisão dialetal do Espanhol da América e analisamos seu reflexo em três dicionários de americanismos. Com este estudo, detectamos muitas discrepâncias, tanto no que diz respeito às teorias dialetológicas quanto às imputações diatópicas fornecidas pelos dicionários de americanismos. Com a nossa proposta, alcançamos uma maior certeza quanto às informações diatópicas, gerando uma confiabilidade sustentada por exemplos empíricos do uso da língua.

Palavras-chave: lexicografia; americanismos; dialetologia.

\begin{abstract}
In this paper we propose a methodology to proceed to the diatopic marking of the Spanish-Portuguese false friends dictionary in a more reliable way. As a starting point, we present a panoramic vision concerning the dialetic division proposals of the American Spanish and analyze its consequences in three Americanisms dictionaries. With this study, we have detected a lot of discrepancies, both in what concerns the dialetological theories as to the diatopics imputations provided by the Americanisms dictionaries. Through our proposal, we reached a higher certainty regarding the diatopic informations, creating a liability sustained by empirical examples of the language use.
\end{abstract}

Key-words: lexicography; americanisms; dialectology.

\section{REFERÊNCIAS}

ALVAR, Manuel. Manual de dialectologia hispánica. Barcelona: Ariel, 1996.

BENEDUZI, Renata. Análise das definições em quatro dicionários semasiológicos da língua portuguesa e propostas de emendas. Ao Pé da letra, Recife, v. 6, n. 2/2, p. 183-190, 2004. 
FORNARI, M. K. A PRoblemÁtica dos AMERICANISMOS: TEORIAS DE DIVISÃo...

BUGUEÑo, Félix. Consideraciones para um nuevo diccionario de falsos amigos españolportugués. Polifonia, Cuiabá, n. 6, p. 103-127, 2003.

Falsos amigos, falsos cognatos, heterossemânticos: uma simples escolha de designações? Organon, Porto Alegre, v. 16, p. 183-192, 2002.

. Problemas macroestruturais em dicionários de falsos amigos. Expressão, Santa Maria (RS), v. 5, n. 1, p. 89-93, 2001.

. A propósito dos dicionários de 'falsos amigos': 'Kritische Würdigung' de HundermarkSantos Martins 1995. Expressão - Revista do Centro de Artes e Letras, Santa Maria, v. 1, jan./jun. 2000.

. Cuán falsos (algunos) amigos! Artexto, Rio Grande, n. 10, p. 73-84, 1999.

CANFIELD, D. Lincoln. El español de América. Barcelona: Crítica, 1988.

[CREA] REAL Academia Española: Banco de datos. Corpus de referencia del Español actual. Disponível em: <http://www.rae.es/>.

[DRAEe] REAL Academia Española. Diccionario de la lengua española. Ed. On-line. Disponível em: <http://www.rae.es/>.

[DUE] MOLINER, María. Diccionario de uso del español. Madrid: Gredos S.A, 1996.

[EvAm] LA CRUZ, Miguel A. Arias de. Diccionario temático de americanismos. 2. ed. La Coruña: Everest, 1987.

HARTMANN, R. R. K. Teaching and researching lexicography. London: Longman, 2001.

LAPESA, Rafael. Historia de la lengua española. 9. ed. Madrid: Gredos, 1988.

LIPSKI, John M. El español de América. 1. ed. Madrid: Cátedra, 1994.

MALMBERG, Bertil. La América hispanohablante. 3. ed. Madrid: ISTMO, 1966.

MORENO de Alba, José G. El español en América. 2. ed. México: Fondo de cultura económica, 1988.

[Mo] MORÍNIGO, Marcos A. Diccionario del español de América. 2. ed. Madrid, 1993.

MOUTON, Pilar García. La división dialectal del español de América: reflexiones y propuesta de trabajo. In: CONGRESO INTERNACIONAL DE LA LENGUA ESPAÑOLA, 2., 2001, Valladolid. Disponível em: <http://congresodelalengua.cervantes.es>. Acesso em: 07 mar. 2002.

SECo, Rafael. La definición lexicográfica. In: Estudios de lexicografía española. Madrid: Paraninfo, 1987. p. 15-45.

[SoAm] SOPENA, Ramón. Diccionario ilustrado de americanismos. 1. ed. Barcelona: Ramón Sopena S.A., 1983.

TRASK, R. L. Dicionário de linguagem e lingüística. Tradução e adaptação: Rodolfo Ilari. São Paulo: Contexto, 2004.

WERNER, Reinhold. Tareas pendientes en la lexicografía del español americano. In: CONGRESO INTERNACIONAL DE LA LENGUA ESPAÑOLA, 2., 2001, Valladolid. Disponível em: <http://congresodelalengua.cervantes.es>. Acesso em: 07 mar. 2002. 


\title{
Anexos
}

\section{Anexo 1 - Sites consultados da Costa Rica:}

\begin{abstract}
-Por dos razones: no me correspondía, el mérito no fue mío y no creo en premios. La gran mayoría son producto de una argolla; usted me lo da a mí, luego yo se lo doy a usted... Hay gente meritoria que nunca ganó premios, como Carmen Granados; otros se han ganado cinco por estar en la argolla. No quiero estar en la misma bolsa con ellos, ni con los que se lo merecen, ni con los que no.
\end{abstract}

(http://www.aldia.co.cr/ad_ee/2005/enero/31/sociedado.html) Acesso em: 19/09/2005.

Pero lo que mas me hace reflexionary entristecerme de la clase de "justicia" que se vive en mi pais, en el sistema tan pasivo del augusto "CMC" $y$ en la poca resistencia de parte de todo aquel medico que se ve afectado por la famosa "argolla", es que despues de todo el proceso criminal y con dinero aun en la bolsa (que no es poco), se le este dando una plaza de lujo a alguien que jugo, humillo y desprestigio a la CCSS, sus colegas y la patria. Es el colmo de la "argolla"!! Esto, cuando hay cientos de colegas honestos con ideas frescas y experiencia laboral igualmente profesionaly sobretodo, con un expediente limpio. Felicidades, Clinica de Hatillo... que disfruten su nuevo director.

(http://www.medicos.sa.cr/Foros/read.php?1,16,121) Acesso em: 19/09/2005.

En los movimientos sindicales muchos se incorporan a la fuerza, por presión de los cabezas calientes y calenturientos rojillos que los obligan a llenar las boletas de inscripción. De lo contrario se verían en el riesgo de sufrir 'inconveniencias' en el desempeño de sus funciones. Y hay quienes adhieren a una organización sindical con el propósito de formar parte de una argolla la cual le podría derivar beneficios para escalar puestos o gozar de privilegios laborales. También para tener la oportunidad de hacer viajes al extranjero con todo pagado mientras la institución estatal le corre el salario como si estuviera trabajando.

(http://www.anfe.or.cr/cl/lib131.htm)

Acesso em: 19/09/2005. 
"El cobro judicial de los créditos hipotecarios que otorga el INS se ha venido realizando de forma irregular desde hace más de 20 años contraviniendo las leyes, por una argolla de abogados de planta de la propia institución y por algunos profesionales externos que en cierto momento trabajaron para la entidad", acotó la diputada Navarro.

(http://www.asamblea.go.cr/actual/boletin/2003/ago03/05ago03.htm) Acesso em: 19/09/2005.

\section{AnEXo 2 - SitEs CONSUltados do EQUADoR:}

Lo primero, porque la Presidencia ha hecho uso discrecional de anticipos a utilidades, ya que el Estado es accionista del BEDE: ha entregado donaciones con una clara intencionalidad para beneficiar a personas públicas y privadas afectas al Gobierno. Lo segundo, porque en el BEDE se ignora la austeridad prometida por Gutiérrez, mientras una 'argolla' de altos funcionarios se benefician de préstamos y sobresueldos de privilegio.

(http://www.sisepuede.com.ec/articulo.php?c $=9 \& \mathrm{~s}=15 \& \mathrm{x}=7 \& \mathrm{a}=2285$ )

Acesso em: 19/09/2005.

Existen hoy muchas explicaciones al fracaso en el manejo de nuestra politica exterior en la designación de embajadores, mas resulta curioso que la histórica argolla del Ministerio de Relaciones Exteriores pueda cometer errores tan infantiles, por lo que tenemos que apuntar más a la mala fe que a la ignorancia.

(http://www.lahora.com.ec/opinioncompleta.asp? seid=3\&opid=14811)

Acesso em: 19/09/2005.

La asociación de círculos familiares son los dueños de todos los privilegios y bondades; los parientes controlan el índice de obediencia y recomiendan, por el récord de arrastramiento, al individuo. Fuera de la argolla de sangres cercanas, por motivos que la razón no entiende, hay algunos que consumen porciones de favores y palmaditas paternales del 'Loco'. (...) Se asumen defensores de los pobres y hacen de la pobreza el mejor recurso a explotar con fáciles y rápidos beneficios para la argolla familiar.

(http://www.hoy.com.ec/NoticiaNue.asp?row_id=183955)

Acesso em: 19/09/2005.

Ya se podrá saber los sueldos de los burócratas dorados, quiénes son los de las argollas de las contrataciones públicas, los montos de tales contratos, 
FORNARI, M. K. A PRoblemática dos Americanismos: teorias de diVISÃo...

los planes de inversiones y de gastos corrientes, etcétera. Tantas cosas que la imaginación se desata. El paraíso, otra vez, a la vuelta de la esquina.

(http://www.sisepuede.com.ec/articulo.php?c $=9 \& s=15 \& \mathrm{x}=7 \& \mathrm{a}=229$ )

Acesso em: 19/09/2005.

\section{Anexo 3 - Sites consultados do Peru:}

La corrupción trae no pocos problemas y muy graves. En primer lugar, el temor a ser descubiertos por algún mando honesto lleva a que los corruptos se defiendan entre ellos formando argollas que luchan por colocar a su gente en los puestos de decisión.

(http://www.desco.org.pe/publicaciones/QH/QH/QH129EO.HTM)

Acesso em: 19/09/2005.

En otro momento de sus declaraciones, el renunciante parlamentario afirmó que dentro de la bancada de Perú Posible existe una 'cúpula' encabezada por el congresista Luis Solari de la Fuente, que ha formado una 'argolla' $y$ 'maneja el poder marginando a los cholitos de provincia".

(http://200.37.28.39/noticia88e7.html?pIdNoticia =12746\&pId=5) Acesso em: 19/09/2005.

Quienes creemos en la convivencia humana no podemos permitir que un impostor, acompañado de su argolla, se proclame redentory único camino de la verdad.

(http://www.correoperu.com.pe/paginas_columna.asp?columna_autor= Hugo $\% 200$ tero\%20L.\&nota_seccion $=8 \&$ nota_id $=6056$ ) Acesso em: 19/09/2005.

Podian estar en su mejor momento, rindiendo futbolísticamente con calidad pero, la "argolla" existente con el beneplácito del comando técnico y la dirigencia, mandaba y los nombres se repetirán en cada convocatoria pese a saberse que, tal o cual jugador, no estaba en el rendimiento necesitado y exigido por la selección nacional.

(http://www.rpp.com.pe/portada/deportes/c_110.php) Acesso em: 19/09/2005. 
FORNARI, M. K. A PRoblemÁtica dos Americanismos: teorias de divisão...

\section{Anexo 4 - Sites consultados de Honduras:}

¿Se romperá por lo más débil la ominosa argolla de los que más tienen?

(http://www.tiempo.hn/edicante/2005/febrero/3/editor 1/editoria.htm) Acesso em: 19/09/2005.

Algunos de estos señores están ejerciendo una gran presión sobre los Diputados para que encuentren la manera de allanar el camino para que sus nombres lleguen hasta la Junta Nominadora y de ahi, una vez ubicados en la lista de los postulados, conseguir el apoyo de las "argollas" de partido que funcionan en el Congreso Nacional.

(http://www.rds.org.hn/docs/noticias/foro_ciudadano_17julio.html) Acesso em: 19/09/2005.

Si la izquierda promoviera un modelo en el que se rompieran las argollas economicas, sin hablar de lesiones a la propiedad privada, entonces hasta yo votaria por ellos. Si surguiera un Lula da Silva hondureño, entoces habrian un oportunidad para la izquierda. Pero si se arraigan al modelo Cubano o el Venezolano (que solo funcionara mientras el precio del petroleo siga alto), no progresaran.

(http://www.proceso.hn/politica/230505_UD.php) Acesso em: 19/09/2005.

Nosotros tuvimos un grupo de jugadores donde había un buen liderazgo, siempre y cuando la argolla sea buena. Tenemos que buscar líderes que unan y que respeten a su equipo. Espero que las famosas argollas sean los nuevos líderes que nazcan de estas Selecciones y que le den al fútbol grandes satisfacciones.

(http://www.elheraldo.hn/ detalle.php? $\mathrm{nid}=24540 \& \mathrm{sec}=5 \&$ fecha $=2005-01-07$ )

Acesso em: 19/09/2005. 
